the desire for unity does not itself create it: surely there will be contest, perhaps debilitating disagreement, over what constitutes the nature of the 'totality', or the relative significance of production relations to the many varieties of human oppression? Invoking Gramsci hardly resolves the issue. Sanbonmatsu proceeds as if the debates over hegemony in the 1970s and 80s, particularly on the European left (and in Italy in particular), had never occurred. Then, at very least, the tensions between Marxist analyses and democratic politics, the view of totality and the need to crystallize a multiplicity of radical aspirations were laid bare.

Sanbonmatsu tries to end his analysis on a positive note, sketching a 'normative ontology' he calls 'metahumanism': a secular framework that incorporates moral regard for nonhuman animals, too, designed to serve as an ethical foundation to his project of civilizational struggle. But this ambitious picture of unification based on inclusive values of love and empathy, and a striving for a deep 'fullness of being', begins to sound less like the sharpened political mindset of the left activist and more the mystical nonsense that the author began by critiquing so effectively. Paradoxically, in the 'Epilogue' Sanbonmatsu retreats from his quest for totality, accepting that 'the desire to know the whole is an insatiable and destructive desire' (p. 225), and he claims to recognize the inevitably 'imperfect unity' a left strategy will forge. But his needless hostility to contemporary continental theory and his grandiose conception of radical politics as a quest for total spiritual transformation suggest the postmodern Prince will struggle to win his crown.

James Martin

Goldsmiths College, University of London, UK.

\title{
Wayward Reproductions: Genealogies of Race and Nation in Transatlantic Modern Thought
}

Alys Eve Weinbaum

Duke University Press, London, 2004, xii $+350 p p$.

ISBN: 0822333011.

Contemporary Political Theory (2006) 5, 231-233. doi:10.1057/palgrave.cpt.9300239

Wayward Reproductions sets out to treat reproduction as a keyword, and to explore how it gets caught up with race, nation and genealogy in the discourses of modernity. Weinbaum prioritizes reproduction as a political concern, and argues for the centrality of what she terms the 'race/reproduction bind' (p. 5) to the modern episteme, and to understanding nationalism, imperialism and racism. This is an ambitious task, and Weinbaum embraces its complexity by 
juxtaposing those she calls 'modernity's big system builders' (p. 11), Engels, Darwin and Freud, with Nietzsche and Foucault, and with less widely known literary and political figures, Charlotte Perkins Gilman, Kate Chopin and W.E. DuBois. As she acknowledges, her attempt to explore these multiple contexts and her refusal to be fenced in by national and disciplinary boundaries is sometimes 'unbearably heterogeneous' (p. 11). This is a dense book, concerned with literature, cultural studies and intellectual history as well as politics and so its chapters are disparate in their concerns, and it says less about the construction of the maternal body as a racializing force than it promises to do at the outset.

That said, the case for foregrounding the 'race/reproduction bind' and the ways in which it naturalizes oppression in a variety of contexts is expertly and convincingly argued. In the first chapter, she sets out the conceptual blind spots in theories of nationalism - the relation of race to nation and of racial nationalism to sexism - and carefully unpicks Benedict Anderson's dissociation of racism and nationalism. Racism and sexism, she argues, cannot be thought separately because reproduction is a racializing force. This insight informs Weinbaum's fascinating and critical discussion of Gilman. She considers Gilman's description of America's 'true' racial stock, her horror of miscegenation, her advocacy of internal colonization, and her proposal for an enlisted army of Negro labour to replace the imported labour of immigrants from South and Eastern Europe and Asia, especially China and Japan. Herland emerges from Weinbaum's account as a defence of purified reproduction, and of a sisterhood that is national, racial and genealogical. The advantages of Weinbaum's multi-layered approach lie in the way she brings together Gilman's fiction and nonfiction in her analysis, and in her critical dissection of the feminist impulse to erase the vexing elements of Gilman's legacy. She uses Gilman as a lever for exploring the investment of 'gender-focused feminism' (p. 91) in building a tradition that ignores the race/reproduction bind. This thoughtful and nuanced approach to the challenge of thinking gender and race together was, for me, one of the great strengths of this book.

The same themes emerge from the discussion of Engels in chapter 3, where Weinbaum analyses his sources and the assumptions that they share. Her argument is that Engels uses Lewis Morgan's formulations about gentile kinship to tell a story not only about the origin of family, private property and the state but also about the German nation, so that nationality and kinship are not antithetical, but supplementary, and kinship systems are constructed as real, organic and biological. Race is then transmitted in the blood, and kinship is a kind of racial category and not a social construct. Engels, she argues, accepted an essentialist reading of race, families and nations that needs to be contested, and that task is more effectively carried out when the race/ reproduction bind is foregrounded rather than erased, and the tricky 
relationships between race, reproduction and class are articulated rather than ignored. Again, this strikes me as a plausible and urgent challenge for those engaged in the difficult project of thinking through gender, race and class.

The chapters on Darwin and Freud, and on W.E. DuBois return to the theme of reproductive racism, and discuss it in ways that are occasionally oblique but often illuminating. Her reading of Freud generates some fascinating insights into how Freud built a new universality for psychoanalysis out of the particularism of denigrated stereotypes of Jewishness. Her contention is that Freud's science was not purged of its Jewishness to universalize it, but that anti-Semitic discourse was reappropriated and reworked, so that a new universality emerged out of 'the racist cacophony' surrounding Freud (p. 166). Once more, Weinbaum insists that the struggle to keep race and sex analytically separate is futile, distorting and ultimately selfserving. In her treatment of DuBois and his concept of racial globality, she finds some sort of conclusion. In 'Dusk to Dawn' she argues, he attempts to understand reproduction not as essential or biological but as genealogical. Of all the thinkers she engages, he comes closest to understanding belonging without recourse to the race/reproduction bind. Troubling essentialism is replaced by the structure of feeling.

Wayward Reproductions is thought provoking, and just provoking. It offers a well-argued, articulate and thoroughly convincing account of the ways in which race has been rendered unspeakable and invisible as a political concept, and of how that very unspokenness reproduces its power. Weinbaum's persistent reminders of the pernicious effects of trying to think race, gender and class into separate categories are salutary and well taken. The difficulty with the erudite and eclectic approach that this book takes is that it becomes elliptical. I was left unsure about just what it is that binds race and reproduction together, and frustrated by the disappearance of the maternal body, by the slippages between gender, sex and sexuality and by the lost questions of property, exploitation and labour that are inseparable from a belonging that is about politics and not just about feeling.

Laura Brace University of Leicester, UK. 